\title{
An Improved Decision-making Model of Multi-objective Extension Design in Product Scheme and Its Application
}

\author{
Ma Zhanbao ${ }^{1}$ and Sun Shuyong ${ }^{2}$ \\ ${ }^{1}$ Henan Vocational and Technical College of Communications, Zhengzhou, \\ Henan, China, 450005 \\ ${ }^{2} X i$ 'an University of Post \& Telecommunications, Xi'an, Shanxi, 710121 \\ mzb129@sina.com, shuyongsun@126.com
}

\begin{abstract}
Due to the multi-objective process of complex product scheme design, the multiobjective design optimization method of product scheme design is studied, an improved decision-making method of multi-objective extension design based on the extension theory is put forward, and a decision-making method of multi-objective extension design model based on the extensible relational degree is presented. By using the method and the model, the characteristic indexes are processed integrated, the computation model of extension degree of association is founded to process the uncertainty design information, and the decision design is achieved based on the optimum degree of the multi-objective design scheme. Finally, a case is provided to prove its feasibility.
\end{abstract}

Keywords: Scheme Design, Multi-objective Design, Decision-making Model, Extension Theory, Artificial Intelligence

\section{Introduction}

The multi-objective design optimization of complex product design scheme is an important component part in the process of product intelligent design. In recent years, the multi-objective design optimization of complex product design scheme has attracted many domestic and foreign scholars' attention, they analyze and discuss the multiobjective design optimization from different angles, and has obtained the corresponding results. At present, the commonly used optimization methods of multi-objective design has fuzzy optimization method [1-2], grey relational analysis [3-4] and artificial intelligence [5-8], etc., Fuzzy optimization method solves the problem of the design optimization with fuzzy design information in some degree, but due to the construction of decision-making membership function is suffered by subjective factors, so it limits the objectivity of the results of optimization. Gray relational analysis method is able to handle poor information in process of optimization of complex product design scheme, but the gray numbers and the albino function sometimes are difficult to determine. And using artificial intelligence method to select design scheme needs to have a large number of training samples of design schemes, but the training data of product design scheme is limited, so it has certain limitations in optimization of complex product design scheme. Extenics as an emerging intelligent design discipline is laws and methods using formal tool to study contradictions from the qualitative and quantitative perspective, and provides a new method to deal with the optimization of complex product design scheme [9-18]. At present, there are some scholars use extenics to study the issues of product design decision and design analysis, and obtain the corresponding results [19-28]. However, currently the application of extenics in optimization of large and complex product design scheme is still not enough, its specific performance: (1) The most studies are simple application of extensible relational function, and ignore the applicability of preferred 
information of different design; (2) The most studies are considering the optimum degree of value of precise point in optimization, and cannot effectively deal with fuzzy information. To this end, this paper presents an improved decision-making model of multi-objective extension design in product scheme, and verifies it by the algorithm.

\section{The Fundamental Concepts of Multi-objective Extension Design Optimization}

\subsection{Matter-element Model and the Relational Function}

Matter-element theory uses matter-element to represent the preferred object which is studied, builds an extension model combined with qualitative and quantitative methods, and describes the degree of the nature changes of the objective things based on the relational function to attain extension analysis of fuzzy contradictions problems.

The matter-element of preferred object consists of preferred object named by $N$, the characteristics of the object named by $C$, and the value of characteristics named by $V$, record it as $\boldsymbol{R}=(N, C, V)$. If optimization of multi-objective extension design has $\mathrm{m}$ preferred characteristics, than its model is as fellow:

$$
\boldsymbol{R}=(N, C, V)=\left[\begin{array}{ccc}
N & c_{1} & v_{1} \\
& c_{2} & v_{2} \\
& \vdots & \vdots \\
& c_{m} & v_{m}
\end{array}\right]
$$

In order to represent the associated attribute between matter-element and design target, extenics puts forward the concept of distance. The classic extension distance can be expressed as:

$$
\rho(v, X)=\left|v-\frac{x_{1}+x_{2}}{2}\right|-\frac{1}{2}\left(x_{2}-x_{1}\right)
$$

Among it, $\rho(v, X)$ represent the distance between the value $v$ and magnitude interval $X$, the magnitude interval $X=\left[x_{1}, x_{2}\right], x_{1} \leq x_{2}$.

Extensible relational function describes the degree of nature change that design object occurs in its characteristics magnitude interval, use it to express the relative degree of design object and design target, and put forward a new problem solving means for multiobjective design of complex product scheme .

\subsection{The Classical Field Matter-element Model and the Segment Field Matter- Element Model}

Assuming the optimal design of complex product scheme has $n$ number of optimization grades, multi-objective optimization has $m$ number of optimum indexes, then its classical field matter-element model can be expressed by $\boldsymbol{R}_{d}$ :

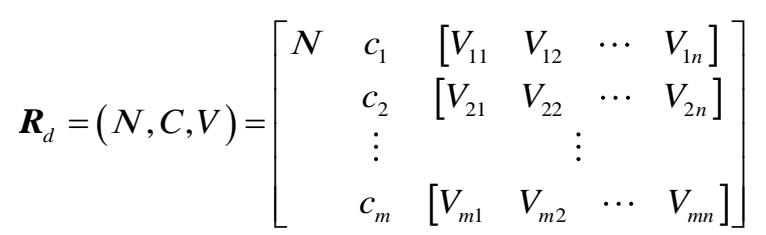

Among it, $V_{i j}=\left[v_{1}^{i j}, v_{2}^{i j}\right]$ is the characteristics magnitude interval that is set by the $j^{\text {th }}$ optimization grade concerning to the $i^{\text {th }}$ optimum index, that is the classical field concerning to its optimum index, and meets $v_{1}^{i j} \leq v_{2}^{i j}, 1 \leq i \leq m, 1 \leq j \leq n$. 
On the basis of the classical field matter-element model, it can form the segment field matter-element model $\boldsymbol{R}_{p}$ :

$$
\boldsymbol{R}_{p}=(N, C, V)=\left[\begin{array}{ccc}
N_{p} & c_{1} & {\left[v_{1}^{1 p}, v_{2}^{1 p}\right]} \\
& c_{2} & {\left[v_{1}^{2 p}, v_{2}^{2 p}\right]} \\
& \vdots & \vdots \\
& c_{m} & {\left[v_{1}^{m p}, v_{2}^{m p}\right]}
\end{array}\right]
$$

Among it, $V_{i p}=\left[v_{1}^{i p}, v_{2}^{i p}\right]$ is the magnitude interval that is set by all $N_{p}$ concerning to the $i^{\text {th }}$ optimum index, that is the segment field, and meets $v_{1}^{i p}=\min _{1 \leq j \leq n}\left(v_{1}^{i j}\right), v_{2}^{i p}=\max _{1 \leq j \leq n}\left(v_{2}^{i j}\right)$.

\section{An Decision-making Model of Multi-objective Extension Design in Product Scheme and Its Algorithm}

\subsection{Fuzzy Matter-element Model of the Preferred Scheme}

Assuming proposed preferred design scheme is $q$, its matter-element model can be structured by preferred design characteristics which already exist. As preferred scheme with given preferred design characteristics often has some uncertainty design information, so the value of characteristics which can be accurately represented may be described by accurate value, for the value of characteristics including uncertainty design information can be described by magnitude interval, and meanwhile, the different preferred characteristics often has different degree of importance, that is having a different preferred characteristics weight, so the fuzzy matter-element model of preferred design scheme $q$ can be expressed by $\boldsymbol{R}_{q}$ :

$$
\boldsymbol{R}_{q}=(N, C, V)=\left[\begin{array}{ccc}
N_{p} & c_{1} & \left(\left[v_{1}^{1 q}(x), v_{2}^{1 q}(x)\right], w_{1}\right) \\
& c_{2} & \left(\left[v_{1}^{2 q}(x), v_{2}^{2 q}(x)\right], w_{2}\right) \\
& \vdots & \vdots \\
& c_{m} & \left(\left[v_{1}^{m q}(x), v_{2}^{m q}(x)\right], w_{m}\right)
\end{array}\right]
$$

Among it, $v^{i q}(x)=\left[v_{1}^{i q}(x), v_{2}^{i q}(x)\right]$ is the magnitude interval that is set by preferred design scheme $q$ concerning to the $i^{\text {th }}$ optimum index, its interval extremum can be calculated by fuzzy membership function, also can be obtained by empirical values. $w_{i}$ is the weight of the $i^{\text {th }}$ optimum index, and meets $w_{1}+w_{2}+\cdots+w_{m}=1$.

\subsection{The Standard Process of Optimum Indexes}

The optimum indexes of complex product design scheme have positive indexes and contrary indexes, different types of positive indexes and contrary indexes commonly have different dimension, and the optimum indexes themselves may include the nature of uncertainty decision-making information. For this reason, the different types of optimum indexes should be normalized, that can more effectively carry out the preferred analysis of multi-objective extension design of complex product scheme.

Assuming preferred design scheme $q$ having $n$ number of optimum indexes $c$, every optimum index $c$ have $m$ number of optimization grades, then the value of preferred 
design scheme $q$ associating to decision-making characteristic $c_{i}$ is $v^{i q}(c)=\left[v_{1}^{i q}(c), v_{2}^{i q}(c)\right]$, the value of every optimization grade associating to decision-making characteristic $c_{i}$ that is the classical field is $V_{i j}=\left[v_{1}^{i j}, v_{2}^{i j}\right], i=1,2, \cdots, n, j=1,2, \cdots, m$.

If decision-making characteristic $c_{i}$ is positive index, then its standardized index is :

$$
\tilde{v}^{i q}(c)=\left[\tilde{v}_{1}^{i q}(c), \tilde{v}_{2}^{i q}(c)\right]=\left(\frac{v_{1}^{i q}(c)}{v_{2}^{i p} \mid \max _{1 \leq j \leq m}\left(v_{2}^{i j}\right)}, \frac{v_{2}^{i q}(c)}{v_{2}^{i p} \mid \max _{1 \leq j \leq m}\left(v_{2}^{i j}\right)}\right)
$$

Its standardized index of the corresponded classical field is:

$$
V_{i j}=\left[\tilde{v}_{1}^{i j}, v_{2}^{i j}\right]=\left(\frac{v_{1}^{i j}}{v_{2}^{i p} \mid \max _{1 \leq j \leq m}\left(v_{2}^{i j}\right)}, \frac{v_{2}^{i j}}{v_{2}^{i p} \mid \max _{1 \leq j \leq m}\left(v_{2}^{i j}\right)}\right)
$$

Its standardized index of the corresponded segment field is:

$$
V_{i p}=\left[\begin{array}{cc}
\sim^{i p} & \sim_{1}^{i p} \\
v_{2}
\end{array}\right]=\left(\frac{v_{1}^{i p}}{v_{2}^{i p} \mid \max _{1 \leq j \leq m}\left(v_{2}^{i j}\right)}, \frac{v_{2}^{i p}}{v_{2}^{i p} \mid \max _{1 \leq j \leq m}\left(v_{2}^{i j}\right)}\right)=\left(\frac{v_{1}^{i p}}{v_{2}^{i p} \mid \max _{1 \leq j \leq m}\left(v_{2}^{i j}\right)}, 1\right)
$$

If decision-making characteristic $c_{i}$ is contrary index, then its standardized index is:

$$
\tilde{v}^{i q}(c)=\left[\tilde{v}_{1}^{i q}(c), \tilde{v}_{2}^{i q}(c)\right]=\left(\frac{v_{1}^{i p} \mid \min _{1 \leq j \leq m}\left(v_{1}^{i j}\right)}{v_{2}^{i q}(c)}, \frac{v_{1}^{i p} \mid \min _{1 \leq j \leq m}\left(v_{1}^{i j}\right)}{v_{1}^{i q}(c)}\right)
$$

Its standardized index of the corresponded classical field is:

$$
V_{i j}=\left[\begin{array}{cc}
\sim_{i j}^{i j}, v_{2}^{i j} \\
v_{2}
\end{array}\right]=\left(\frac{v_{1}^{i p} \mid \min _{1 \leq j \leq m}\left(v_{1}^{i j}\right)}{v_{2}^{i j}}, \frac{v_{1}^{i p} \mid \min _{1 \leq j \leq m}\left(v_{1}^{i j}\right)}{v_{1}^{i j}}\right)
$$

Its standardized index of the corresponded segment field is:

$$
V_{i p}=\left[\tilde{v}_{1}^{i p}, \tilde{v}_{2}^{i p}\right]=\left(\frac{v_{1}^{i p} \mid \min _{1 \leq j \leq m}\left(v_{1}^{i j}\right)}{v_{2}^{i p}}, \frac{v_{1}^{i p} \mid \min _{1 \leq j \leq m}\left(v_{1}^{i j}\right)}{v_{1}^{i p}}\right)=\left(\frac{v_{1}^{i p} \mid \min _{1 \leq j \leq m}\left(v_{1}^{i j}\right)}{v_{2}^{i p}}, 1\right)
$$

It can be seen that the normalized design scheme indexes meet $0 \leq \tilde{v}_{1}^{i q}(c) \leq 1,0 \leq \tilde{\sim} \tilde{v}_{2}^{i q}(c) \leq 1$; the indexes of the corresponded classical field meet $0 \leq \tilde{v}_{1}^{i j} \leq 1, \quad 0 \leq \tilde{v}_{2}^{i j} \leq 1$; the indexes of the corresponded segment field meet $0 \leq \tilde{v}_{1}^{i p} \leq 1, \tilde{v}_{2}^{i p}=1$; Thus, all of the optimum indexes' scheme value, the classical field and segment field have an unified measure standards, it eliminates the differences between the indexes and more conducive to accuracy of the preferred measure .

\subsection{The Construction of Extension Preferred Relational Function}

After standardizing the optimum indexes, it need to analysis the relative degree of every optimum indexes and its associated classical field and segment field, for that, it should construct its extension distance, extensible relational function and extensible relative degree. 
On the basis of formula(2), the extension distance between the value of preferred design scheme $q$ associating to decision-making index $\tilde{\sim}_{v}^{i q}(c)=\left[\tilde{\sim}_{v_{1}}^{\sim i q}(c), \tilde{\nu}_{2}^{i q}(c)\right]$ and the value of the classic field $V_{i j}=\left[\begin{array}{cc}\sim_{v_{1}^{i j}} & \sim_{v}^{i j} \\ v_{2}\end{array}\right]$ can be expressed by $\rho\left(\tilde{v}^{i q}(c), V_{i j}\right)$ :

$$
\rho\left(\tilde{v}^{i q}(c), V_{i j}\right)=\frac{1}{2}\left(\rho\left(\tilde{v}_{1}^{i q}(c), V_{i j}\right)+\rho\left(\tilde{v}_{2}^{i q}(c), V_{i j}\right)\right)
$$

On the basis of formula(2), the extension distance between the value of preferred design scheme $q$ associating to decision-making index $\tilde{v}_{v}^{i q}(c)=\left[\tilde{\sim}_{v_{1}}^{i q}(c), \tilde{v}_{2}^{i q}(c)\right]$ and the value of the segment field $V_{i p}=\left[\begin{array}{cc}\tilde{v}_{1}^{i p}, \tilde{v}_{2}^{i p} \\ v^{2}\end{array}\right]$ can be expressed by $\rho\left(\tilde{v}^{i q}(c), V_{i p}\right)$ :

$$
\rho\left(\tilde{v}^{i q}(c), V_{i j}\right)=\frac{1}{2}\left(\rho\left(\tilde{v}_{1}^{i q}(c), V_{i p}\right)+\rho\left(\tilde{v}_{2}^{i q}(c), V_{i p}\right)\right)
$$

Then the extensible relational function of preferred design scheme $q$ associating to the $j^{\text {th }}$ classic field of the $i^{\text {th }}$ decision index can be expressed by $K_{i j}\left(\tilde{v}^{i q}(c), V_{i j}\right)$ :

$$
K_{i j}\left(\tilde{v}^{i q}(c), V_{i j}\right)=\left\{\begin{array}{cc}
-\frac{\rho\left(\tilde{v}^{i q}(c), V_{i j}\right)}{\left|V_{i j}\right|} & \tilde{v}^{i q}(c) \in V_{i j} \\
\frac{\rho\left(\tilde{v}^{i q}(c), V_{i j}\right)}{\rho\left(\tilde{v}^{i q}(c), V_{i p}\right)-\rho\left(\tilde{v}^{i q}(c), V_{i j}\right)} & \tilde{v}^{i q}(c) \notin V_{i j}
\end{array}\right.
$$

That is

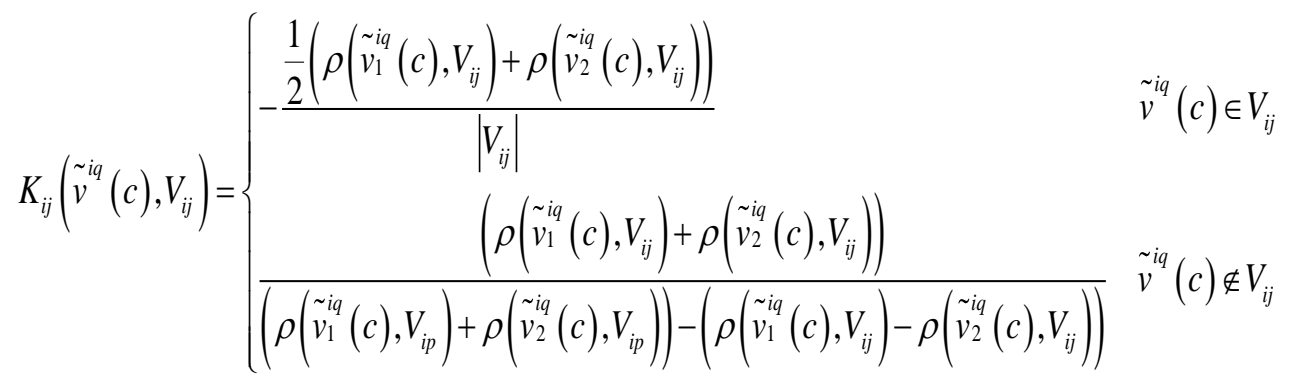

For every optimum indexes $c_{i}$, take its weight coefficient $w_{i}$, and meets $w_{1}+w_{2}+\cdots w_{n}=1$, then the extensible relative degree of design scheme associated to the $j^{\text {th }}$ classic field is $\Psi_{j}$ :

$$
\Psi_{j}=\sum_{i=1}^{n}\left(w_{i} * K_{i j}\left(\sim^{i q}(c), V_{i j}\right)\right)
$$

According to the preferred decision-making standards of maximum integrated extension relative degree, if

$$
\Psi_{0}=\max _{1 \leq k \leq m}\left(\Psi_{k}\right)
$$

Then it can judge that the optimization grade of design scheme $q$ belongs to the category $k$. 


\subsection{The Extension Preferred Model of Multi-objective Design and its Algorithm}

According to constructing the preferred design scheme's decision-making index matter-element model, the classical field matter-element model and the segment matterelement model, normalizing optimum indexes, establishing the extension distance of preferred design scheme, and obtaining its associated extensible relational function, to acquire extensible relative degree of design scheme. And to determine the grade of design scheme on the basis of the size of extension relative degree, finally obtain the category of design scheme. Figure 1 gives the basic framework of multi-objective design extension optimization of product design scheme.

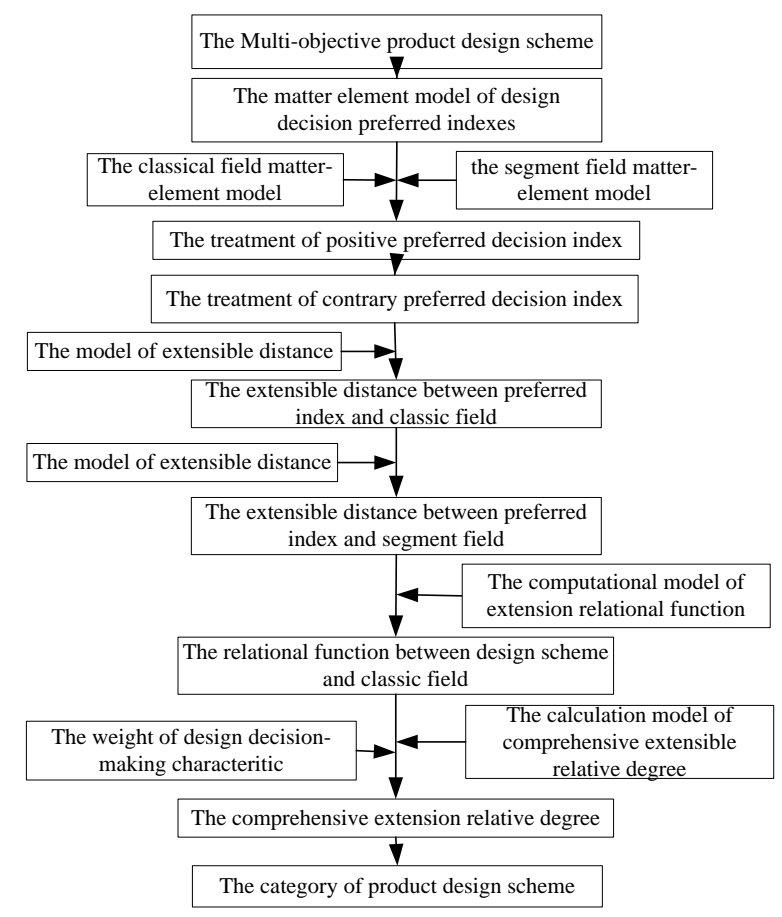

\section{Figure 1. The basic Framework of Multi-objective Design Extension Optimization of Product Design Scheme}

In summary, the concrete implementation steps of multi-objective design extension optimization of product design scheme are as below:

Step1: On the description in chapter 2.1 and chapter 2.2, to construct the design decisions preferred scheme's decision-making index matter-element model, the classical field matter-element model and the segment matter-element model.

Step2: Aiming at decision-making index matter-element model of design decision preferred scheme that has established, to carry out positive decision preferred indexes, the classic field and the segment field standardized treatment on the basis of formula(6) to formula $(8)$.

Step3: Aiming at decision-making index matter-element model of design decision preferred scheme that has established, to carry out contrary decision preferred indexes, the classic field and the segment field standardized treatment on the basis of formula(9) to formula(11).

Step4: Using formula (12) and formula (13), separately calculate the extensible distance between the preferred indexes and their classic fields and the extensible distance between the preferred indexes and their segment fields. 
Step5: Using formula (14) and formula (15), separately calculate the extensible relational function between the preferred indexes and their classic fields and the extensible distance between the preferred indexes and their segment fields

Step6: Consider the weight of the preferred indexes on the basis of formula (16), calculate the comprehensive extensible relative degree between design scheme and the different classic fields.

Step7: Sorting the design schemes by the size of comprehensive extension relative degree based on formula (17) to judge the category of design scheme's optimization grade.

\section{Case Application}

It uses preferred decision-making of a power plant design scheme to verify the above model and algorithm. According to the experience in the field of design, select the main six decision indexes of operational efficiency, output power, cavitation erosion property, cost, operating stability and device compact as the preferred decision indexes. And the category of design scheme can be divided into four grades, from the highest to lowest in rank, they are excellent, good, secondary and poor.

The decision-making data of a power plant design scheme is known, among it, the operational efficiency, output power, cavitation erosion property and cost are quantitative indexes; The operating stability and device compact are qualitative indexes, they need to be transformed to the fuzzy interval of quantitative indexes. Establish its fuzzy matterelement model $\boldsymbol{R}_{q}$ :

$$
\boldsymbol{R}_{q}=\left[\begin{array}{ccc}
\text { Power plant } A O & \text { Operational efficiency } & ([0.895,0.905], 0.250) \\
& \text { Output power(KW) } & ([46.25,47.30], 0.300) \\
\text { Cavitation erosion property } & ([0.126,0.131], 0.100) \\
\text { Cost }(\text { ten thousand }) & ([17.65,18.25], 0.050) \\
\text { Operating stability } & ([0.873,0.895], 0.250) \\
\text { Device compact } & ([0.795,0.816], 0.050)
\end{array}\right] ;
$$

Through consulting the experts of this field, to acquire the classic field of excellent, good, secondary and poor of every preferred decision indexes. It should be noted here that according to the design experience of this field, the preferred decision indexes of operational efficiency, output power, operating stability, device compact must meet the condition, that is they must meet threshold requirements, then the design scheme can be carried out, thus, when establish their classic field and segment field, the values are not starting from zero. The classic field matter element model of four levels are $\boldsymbol{R}_{d 1}, \boldsymbol{R}_{d 2}, \boldsymbol{R}_{d 3}, \boldsymbol{R}_{d 4}:$

$\boldsymbol{R}_{d 1}=\left[\begin{array}{ccc}\text { Excellent } & \text { Operational efficiency } & {[0.920,1.000]} \\ & \text { Output power(KW) } & {[48.00,50.00]} \\ & \text { Cavitation erosion property } & {[0.080,0.100]} \\ \text { Cost (ten thousand) } & {[12.000,15.000]} \\ & \text { Operating stability } & {[0.950,1.000]} \\ & \text { Device compact } & {[0.900,1.000]}\end{array}\right] ;$




$$
\begin{aligned}
& \boldsymbol{R}_{d 2}=\left[\begin{array}{ccc}
\text { Good } & \text { Operational efficiency } & {[0.890,0.920]} \\
& \text { Output power(KW) } & {[45.00,48.00]} \\
& \text { Cavitation erosion property } & {[0.100,0.120]} \\
& \text { Cost }(\text { ten thousand }) & {[15.000,17.000]} \\
& \text { Operating stability } & {[0.900,0.950]} \\
& \text { Device compact } & {[0.850,0.900]}
\end{array}\right] ; \\
& \boldsymbol{R}_{d 3}=\left[\begin{array}{ccc}
\text { Secondary } & \text { Operational efficiency } & {[0.800,0.890]} \\
& \text { Output power(KW) } & {[40.00,45.00]} \\
& \text { Cavitation erosion property } & {[0.120,0.140]} \\
& \text { Cost }(\text { ten thousand }) & {[17.000,18.500]} \\
& \text { Operating stability } & {[0.800,0.900]} \\
& \text { Device compact } & {[0.800,0.850]}
\end{array}\right] ; \\
& \boldsymbol{R}_{d 4}=\left[\begin{array}{ccc}
\text { Poor } & \text { Operational efficiency } & {[0.750,0.800]} \\
& \text { Output power(KW) } & {[30.00,40.00]} \\
& \text { Cavitation erosion property } & {[0.140,0.160]} \\
& \text { Cost }(\text { ten thousand) } & {[17.650,20.000]} \\
& \text { Operating stability } & {[0.750,0.800]} \\
& \text { Device compact } & {[0.700,0.800]}
\end{array}\right]
\end{aligned}
$$

On the basis of above classic fields, to acquire the segment field of its preferred decision design scheme and establish its segment field matter element model $\boldsymbol{R}_{p}$ :

$$
\boldsymbol{R}_{p}=\left[\begin{array}{ccc}
\text { Preferred segment field } & \text { Operational efficiency } & {[0.750,1.000]} \\
& \text { Output power(KW) } & {[30.00,50.00]} \\
& \text { Cavitation erosion property } & {[0.800,0.160]} \\
& \text { Cost (ten thousand) } & {[12.000,20.000]} \\
& \text { Operating stability } & {[0.750,1.000]} \\
& \text { Device compact } & {[0.700,1.000]}
\end{array}\right] ;
$$

Through the description in chapter 3.2, preferred decision indexes are standardized to acquire fuzzy matter element model $\boldsymbol{R}_{q}$, the classic field matter element model $\boldsymbol{R}_{d}$ and the classic field matter element model $\boldsymbol{R}_{p}$ :

$$
\boldsymbol{R}_{q}=\left[\begin{array}{ccc}
\text { Power plant } A O & \text { Operational efficiency } & ([0.895,0.905], 0.250) \\
& \text { Output power(KW) } & ([0.925,0.946], 0.300) \\
& \text { Cavitation erosion properties } & ([0.611,0.635], 0.100) \\
\text { Cost }(\text { ten thousand }) & ([0.656,0.680], 0.050) \\
\text { Operating stability } & ([0.873,0.895], 0.250) \\
\text { Device compact } & ([0.795,0.816], 0.050)
\end{array}\right] ;
$$




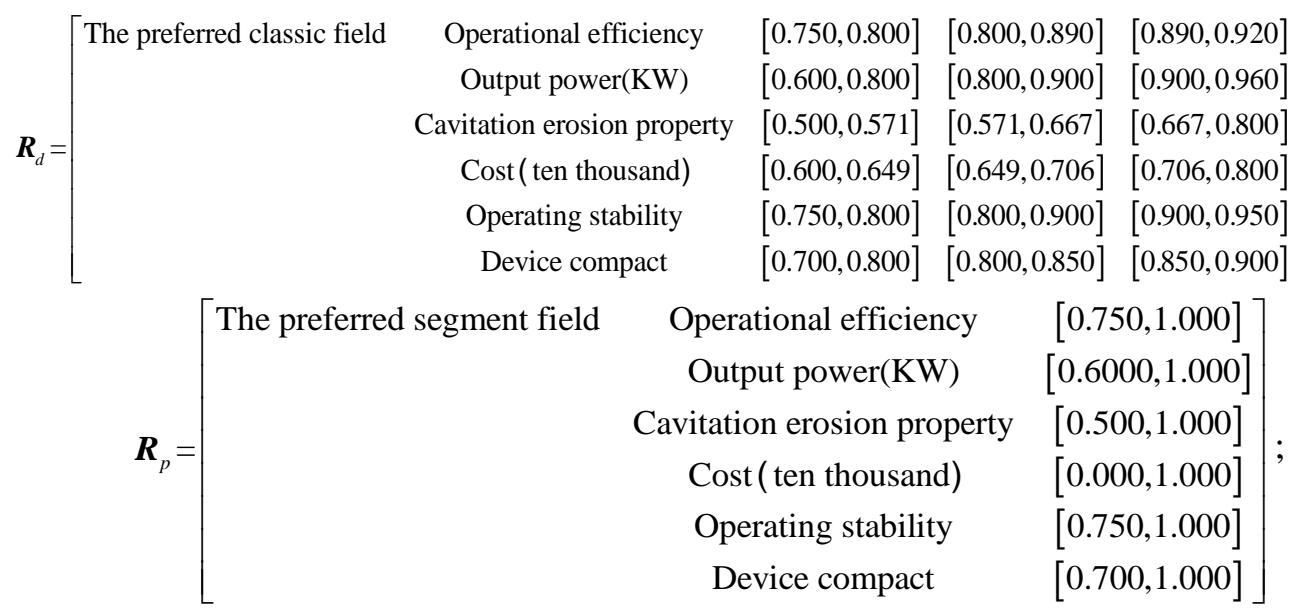

Using formula(12) and formula(13) to acquire the extensible distance matrix $\boldsymbol{\rho}_{V}$ and the extensible distance sequence $\boldsymbol{\rho}_{p}$ associated to preferred decision indexes and their classic fields and segment fields:

$$
\begin{gathered}
\boldsymbol{\rho}_{V}=\left[\begin{array}{cccc}
0.100 & 0.010 & -0.010 & 0.020 \\
0.136 & 0.036 & -0.019 & 0.025 \\
0.052 & -0.036 & 0.044 & 0.177 \\
0.190 & -0.017 & 0.038 & 0.132 \\
0.084 & -0.016 & 0.016 & 0.066 \\
0.006 & -0.006 & 0.045 & 0.095
\end{array}\right] ; \\
\boldsymbol{\rho}_{p}=(-0.200,-0.065,-0.123,-0.068,-0.114,-0.045) .
\end{gathered}
$$

Using formula (14) and formula (15), to acquire the extension relational function matrix $\boldsymbol{K}$ between the preferred decision indicator and its classic field and its segment field:

$$
\boldsymbol{K}=\left[\begin{array}{cccc}
-0.333 & -0.048 & 0.333 & -0.091 \\
-0.678 & -0.355 & 0.317 & -0.275 \\
-0.297 & 0.375 & -0.263 & -0.590 \\
-0.736 & 0.290 & -0.358 & -0.660 \\
-0.424 & 0.160 & -0.123 & -0.367 \\
-0.109 & 0.110 & -0.497 & -0.140
\end{array}\right] ;
$$

On the basis of formula (16), calculate the comprehensive extensible relative degrees sequence $\Psi$ between design scheme and the different classic fields:

$$
\Psi=(-0.460,-0.031,0.098,-0.262) \text {; }
$$

According to the merit principle, it can be very visually determine the optimization grade is good. In order to let it better meet the design requirements and achieving excellent grades, it need to carry out extension adaptive design based on the preferred result. Due to space limitations, the author will analyze it in another paper.

\section{Conclusion}

The paper puts forward an improved decision-making model of multi-objective extension design in product scheme, Through establishing the fuzzy matter element model of preferred information, the model can formally and modeling describe the design preferred indexes; Through normalizing design preferred indexes, make extensible preferred classical field and extension field more adaptive; At the same time, through introducing an improved preferred extension relative function to make the result of preferred extension multi-objective design more integral and coincidental, then the result 
of preferred design is more credible. It provides a new solution for the smooth implementation of the intelligent design of complex products, and provides a theoretical basis for the computer-aided product design, and has important significance in academic and valuable in engineering.

\section{References}

[1] L.-J. Li and L.-T. Shen, "An improved multilevel fuzzy comprehensive evaluation algorithm for security performance", The Journal of China Universities of Posts and Telecommunications, vol. 13, no. 4, (2006), pp. 48 53.

[2] H. Liu, W. Chen, Z. Kang, et al., "Fuzzy Multiple Attribute Decision Making for Evaluating Aggregate Risk in Green Manufacturing", Tsinghua Science \& Technology, vol. 10, no. 5, (2005), pp. 627 632.

[3] Z. Guangming, J. Ru, H. Guohe, et al., "Optimization of wastewater treatment alternative selection by hierarchy grey relational analysis", Journal of Environmental Management, vol. 82, no. 2, (2007), pp. 250 259.

[4] O. Durán and J. Aguilo, "Computer-aided machine-tool selection based on a Fuzzy-AHP approach", Expert Systems with Applications, vol. 34, no. 3, (2006), pp. 1787 1794.

[5] Z. Ayag, "An integrated approach to evaluating conceptual design alternatives in a new development environment", International Journal of Production Research, vol. 43, no. 4, (2005), pp. 687 713.

[6] L. V. Vanegas and A. W. Labib, "Fuzzy approaches to evaluation in engineering design", ASME Journal of Mechanical Design, vol. 127, no. 1, (2005), pp. 24-33.

[7] Y. W. Zhao and G. X. Zhang, "A New Integrated Design Method Based On Fuzzy Matter-Element Optimization", Journal of Materials Processing Technology, vol. 129, no. 1-3, (2012), pp. 612-618.

[8] T.-C. Wang, A.-J. Yang, S.-S. Zhong and Z.-D. Zhao, "Extension Adaptive Design Model Of Scheme Design For Complex Mechanical Products", Tehnički vjesnik/Technical Gazette, vol. 21, no. 1, (2014), pp. 123-133.

[9] Z. Yanwei, S. Nan, Z. Peng, et al., "Custom-oriented product configuration design by extension theory", Journal of Harbin Institute of Technology, vol. 38, no. 7, (2006), pp. 1153-1155.

[10] T.-C. Wang, A.-J. Yang and S.-S. Zhong, "Multi-Attribute Extension Fuzzy Optimized DecisionMaking Model Of Scheme Design”, Tehnički vjesnik/Technical Gazette, vol. 21, no. 2, (2014), pp. 239247.

[11] D. Liu and Z. Zou, "Water quality evaluation based on improved fuzzy matter-element method", Journal of Environmental Sciences, vol. 24, no. 7, (2012), pp. 1210-1216.

[12] J. Gong, Y. Liu and W. Chen, "Land suitability evaluation for development using a matter element model", A case study in Zengcheng, Guangzhou, China, Land Use Policy, vol. 29, no. 2, (2012), pp. 464-472.

[13] Y.-X. He, A.-Y. Dai, J. Zhu, et al., "Risk assessment of urban network planning in china based on the matter-element model and extension analysis", International Journal of Electrical Power \& Energy Systems, vol. 33, no. 3, (2011), pp. 775-782.

[14] Y. Chen, D. S. Liu, J. C. Wu, et al., "Extension based clustering method an approach to support adaptable design of the product", Proceedings of the 2007 International Manufacturing Science And Engineering Conference, Atlanta, Georgia, USA, (2007) October 15-17, pp. 1-9.

[15] T.-C. Wang, A.-J. Yang and S.-S. Zhong, "Products Extension Adaptive Design Based on Case Reuse", International Journal of Control and Automation, vol. 7, no. 1, (2014), pp. 295-306.

[16] A. Li, J. Jiang, J. Bian, et al., "Combining the matter element model with the associated function of probability transformation for multi-source remote sensing data classification in mountainous regions", ISPRS Journal of Photogrammetry and Remote Sensing, vol. 67, (2012), pp. 80-92.

[17] M.-H. Wang, Y.-F. Tseng, H.-C. Chen, et al., "A novel clustering algorithm based on the extension theory and genetic algorithm", Expert Systems with Applications, vol. 36, no. 4, (2009), pp. 8269-8276.

[18] N. Su, Y. Zhao, L. Xing, et al., "A variant module division method on Extension logic for assembly process", ASME International Mechanical Engineering Congress and Exposition, Boston, Massachusetts, USA, (2008) October 31-November 6, pp. 1-10.

[19] Y.-C. Yin, L.-F. Sun and C. Guo, "A policy of conflict negotiation based on fuzzy matter element particle swarm optimization in distributed collaborative creative design", Computer-Aided Design, vol. 40, no. 10-11, (2008), pp. 1009-1014.

[20] J. Chun-Rong and Z. Jun, "Based on Fuzzy Weight Matter Element to Evaluate the Water Quality of Jialing River in Nanchong, China", Procedia Environmental Sciences, vol. 11, (2011), pp. 631-636.

[21] L. Yang, "Assessment of City Environmental Quality in Western China Based on Matter Element Extension-a Case Study Of Chongqing", Energy Procedia, vol. 5, (2011), pp. 619-623.

[22] J. Chun-Rong and Z. Jun, "Evaluation of Regional Circular Economy Based on Matter Element Analysis", Procedia Environmental Sciences, vol. 11, (2011), pp. 637-642.

[23] G. Jingzhong, Q. Jing, L. Guoxi, et al., "Product configuration design based on extension theory", Computer Integrated Manufacturing Systems, vol. 13, no. 9, (2007), pp. 1700-1709.

[24] Y. F. Chen, D. S. Liu, J. C. Wu, et al., "A Local Fiscal Health Index Model Based on Extended Matter- 
Element Evaluation", AASRI Procedia, vol. 1, (2012), pp. 394-399.

[25] W. Guiping, J. Yazhou and Z. Guangwen, "Evaluation Method and Application of CNC Machine Tool's Green Degree Based on Fuzzy-EAHP”, Journal of Mechanical Engineering, vol. 46, no. 3, (2010), pp. 141-147.

[26] W. Ti-Chun, Y. Ai-Jun and B. U. Liang-Feng, "Mechanism scheme design based on multi-attribute extension gray relevant optimized decision-making model", Systems Engineering -Theory \& Practice, vol. 33, no. 9, (2013), pp. 2321-2329.

[27] M. Hui, Z. Shuyou, T. Jianrong, et al., "Method on the Reuse of Product Design Process based on Affair-matter Element", Chinese Journal of Mechanical Engineering, vol. 42, no. 3, (2006), pp. 110-116 (in Chinese).

[28] M.-H. Wang and Y.-F. Tseng, "A novel analytic method of power quality using extension genetic algorithm and wavelet transform”, Expert Systems with Applications, vol. 38, no. 10, (2011), pp. 1249112496. 
International Journal of $u-$ and e- Service, Science and Technology Vol.8, No. 10 (2015) 